\title{
THE ROLE OF THE LOCAL AUTHORITY IN RELATION TO HEALTH LEGISLATION
}

\author{
Colin R. Mackenzie
}

\author{
Medical Officer of Health, Durban Local Authority \\ Address given at an International Mental Health Symposium held in Pretoria in March 1979
}

\section{INTRODUCTION}

$\mathbf{T}$ HE underlying philosophy of the Health Act in relation to the three tiers of Government rendering health services in South Africa is to establish flexibility of functions and so to meet local needs and to use local resources to the best advantage. Implicit in this is a coordination of the activities of all three tiers of Government, at the same time involving the services of welfare and other organisations. Overlapping and repetition of services should thus be eliminated. This latter feature is of particular importance if energy, time and money is not to be wasted.

Let me emphasise again that co-ordination and cooperation between the three tiers of government winds like a silver thread through the Health Act of 1977.

In so far as local authorities are concerned, the Act states quite positively that it shall render services for the promotion of the health of persons within its district and co-ordinate such services with due regard to similar services rendered by the Department of Health or the Provincial Administration.

The spelling out in detail of exactly what personal services each tier shall actually render is still the subject of discussion by the Health Advisory Committee.

None the less it is in the Act that Provincial Administrations shall provide facilities for the treatment of the acutely mentally ill and the State, so far, has been caring for the sub-acute and chronically ill.

But treatment, per se, is far from the whole handling of the mentally ill, so let us examine the role of the local authority.

\section{THE ROLE OF THE LOCAL AUTHORITY}

(A) In the Field: There must be few local authorities of any size who do not have at their disposal the services of one or more community nurses, or as they are more popularly called, health visitors. As the very name implies, these highly qualified sisters visit the homes of persons suffering from infectious diseases including tuberculosis, families with infant feeding problems ranging through physical disabilities to the aged.

Can they play a part in the overall treatment of mental illness? Very easily. They have and are doing so now. A few examples from the City of Durban will illustrate the point.
Firstly, with the co-operation of the State Health Department, one health visitor of each of the race groups, i.e White, Coloured and Indian, have undertaken the One-Year Psychiatric Nurses Training Course, whilst a Black is currently undergoing training. This then forms the hard core of psychiatric knowledge amongst the health visitors.

Secondly, the principal psychiatrist of a provincial hospital in Durban (Addington) lectured first weekly and now with a clinical psychologist twice per month to the whole health visiting staff - gearing their lectures initially to imparting basic knowledge, then to specific problems which their own work demonstrates to be commonplace and finally to running the discussion on a seminar basis, where the health visitors can relate specific problems - not, of course, bringing patients! - and they can then give answers in principle. Thus there is a continual interchange of knowledge between the teacher, the pupils and between themselves, all to the benefit of the community, for it is the solution and cure of its problems and ill-health that is at stake.

Thirdly, the health visitors visit mentally ill patients in the course of their duties in each of their districts in the City.

These visits arise through:-

(a) recognition of the illness by themselves in the course of home visiting;

(b) requests from mothers which may be direct or from the family health clinics where child behaviour patterns suggest a problem in the family;

(c) follow-ups of infants and toddlers seen in family health clinics where more detailed observation of the child is required to make an assessment;

(d) a more recent development and one of singular importance is that discharges from certain hospitals are specifically notified to this Department. In these cases, progress, post hospitalisation clinic attendance, regular taking of medication, and observation of the patient are all undertaken. Naturally referral back to clinic when required, with progress reports, play a big part.

Also explanations to, encouragement of the parents and various other facets of importance receive attention. Here it is emphasised that involvement and cooperation with the social worker runs simultaneously. 


\section{(B) Clinic Attendances}

My department has a number of purpose-designed family health clinics and with City Council authority these can be utilized by the State/Health Department at my discretion. So far, three clinics, two for Indians and one for Coloured persons are each being used on certain days when the premises are free, the staff being wholly State, for psychiatric clinic sessions.

In these circumstances an easy cross-referral system to other services can operate fully - in fact family planning by 3 -monthly injection is readily available for those so retarded as to cause continual anxiety to their parents. Furthermore, the community's confidence in the family health clinic is extended to the psychiatric clinic.

Looking only a little way into the future there seems to be no reason why therapy, either in the form of pills or injection (e.g. Modecate for schizophrenic patients) could not be given to the patient at his/her nearest family health clinic, provided only that medicaments are supplied already made up for the patients by the psychiatric service.

In this combined approach with the Local Authority Health Department, it has become apparent that only the fringe of the problem of mental ill health is being tackled. The size of the problem of mental ill health can be illustrated by a few simple statistics:

There were nearly 500 visits by health visitors for mental ill health reasons to homes during 1978 , the inception year of the home visiting.

The clinic attendances were:

\section{Chatsworth - Unit 6 - 2 sessions per week}

1942 per month

Austerville - 1 session per week

228 per month

1978 total attendances: 23306

However, in 1979, Chatsworth Unit 6 closed down and the Clinics in Units 2 and 10 were started, as they were more conveniently situated.

\section{(C) Referrals}

Interspersed with these activities, both in the field and at the clinics, many other organisations have their roles. These are mainly welfare organisations, in particular the Mental Health Society to whom referrals are made in the majority of instances and from whom, obviously, referrals are received.

These referrals relate not only to the activities of their social workers, but also to the general activities of the Society, not excluding their excellent protected workshops and their health education function.

\section{(I)) Health Education}

The Local Authority Health Department in Durban has a strong health education section - some 30 strong, with backing by photographers, technicians and the like. Unlike the health visitors, whose teaching is on a face-to-face or at the most small-group basis, the health education unit is geared to dealing with large groups and communities. The conception of mental health as opposed to mental ill health is one of their targets. Also by dissemination of knowledge early detection becomes a reality - awareness of problems becomes commonplace, sources of help well known and perhaps, most important of all, an interest and a desire for a healthful existence is engendered. Much time is devoted to both mental health and ill health and the latter has been demonstrated by the clinic attendances. Cases of mental ill health are no longer hidden, covered up or neglected for the parallel between mental and physical ill health or fitness is always drawn.

\section{(E) Community Liaison}

A full team of social workers from the City Health Department, practising NO case or group work at all but only community development, are always in the field.

They seek the community's needs, crystallise them and throw the ball back to the community to resolve their problems in terms of their own resources.

So far a good deal of headway has been made by the formation of groups (Wentworth Improvement Project) based on gangs where their energy is redirected from vandalism, drug-taking, mugging and the like to environmental improvement, clearing of land for sports fields and involvement in community activities such as sports clubs.

\section{(F) Co-ordination}

In this sphere an enormous amount of activity has taken place in the Durban area and again in accord with the principles of co-operation and co-ordination so clearly set out in the Health Act.

The role of the local authority in this instance has perhaps been fortuitous. For several years a loosely formed committee of co-ordination had existed but met only very occasionally when the various individuals involved simply got to know one another and perhaps a little of each other's activities. Doubtless also to share amazement at the wonders of bureaurcracy.

However, in July 1978 a meeting was convened at King George V Hospital when a seminar and workshop were held. At the conclusion of this meeting it was decided to establish a definite psychiatric co-ordinating committee and members were nominated and elected to serve thereon under the chairmanship of the Medical Officer of Health. Representation was from:

The State Health Department............. 4 Provincial Administration................. 4 Department of Social Welfare \& Pensions........ 1 Local Authority. ................... 2 Private Psychiatrist.................... Social Agencies: Durban Mental

Health Society.................... University of Natal Medical School............ 1

The terms of reference of the Committee had to be drawn up by the Committee itself, so were simple:

(a) exchange information about existing psychiatric services;

(b) explore and prevent duplication of service;

(c) improve the utilization of existing facilities and manpower through greater co-operation;

(d) investigate proposals to improve or upgrade services.

The Chairman was charged with the overall duty of putting forward any recommendations to the appropriate authority.

The minutes would be available to the Secretary for Health and could be used by the Natal representative of 
the Psychiatric Co-ordinating Committee set up under the Health Matters Advisory Committee.

Six sub-committees were established at the first meeting with their respective chairmen, viz.:

1. Community Psychiatric Social Work Co-ordinating Sub-Committee: Chairman: Dr. T. Jonker (Director of Durban Mental Health Society)

2. Community Nursing Services Co-ordinating SubCommittee: Chairman: Chief Nursing Officer, City Health Dept., Durban.

3. Educational Sub-Committee: Chairman: Professor R. W. S. Cheetham, prof. of Psychiatry, Natal University Medical School.

4. Child Psychiatric Services Sub-Committee: Professor A. L. Behr, Professor of Educational Psychology, University of Durban-Westville.

5. Psycho-Geriatric Sub-Committee: Dr. M. Barlow, Senior Medical Superintendent, Addington Hospital.

6. Clinical Sub-Committee: Dr. A. Levin, Principal Psychiatrist, Addington Hospital.

Each sub-committee chairman was charged with the duty of forming a sub-committee of persons most able to help in his/her field. Each sub-committee's term of reference was simple: to decide upon their FIRST priority and report the possible solutions to the main committee within 1 month.

The main Committee has met on six occasions. Let us look, albeit cautiously, at the achievements and although these may sound nebulous they are very far from being so:-

(1) a sense of urgency coupled with enthusiasm and a very real enthusiasm at that, has been engendered. Nearly everyone on the Committee and SubCommittees work in their own time;

(2) a sharing and understanding of each other's problems has become noticeably obvious;

(3) co-ordination of activities is enormous and the extent of this can be gauged by looking at the composition of some of the sub-committees:

for example:

Psychiatric Social Work Sub-Committee

Department of Indian Affairs

Department of Coloured Affairs

Department of Social Welfare and Pensions

S.A.N.E.L. (South African National Epilepsy

League)

Durban Child Welfare Society

Durban Indian Child Welfare Society

Child Welfare Society for Blacks

Life Line

Addington Hospital

King Edward VIII Hospital

R.K. Khan Hospital

S.A.N.C.A.D.D.

This sub-committee at once saw that there was a gross duplication of services due to the lack of social work case registers for Coloureds, Indians and Blacks - patients from these groups were attending different bodies for the same purpose. A strong move, backed by the State Health Department is afoot to establish case registers similar to those kept by the Department of Social Welfare and Pensions (White) for use by profes- sional staff of the Departments of Indian and Coloured Affairs and by the Bantu Boards.

Other areas, in priority or even deficiency emerged i.e. lack of sheltered employment; lack of information on existing resources; the need to recruit and train volunteers to fill the gap caused by the lack of social workers and so I could carry on.

\section{Community Nursing Services Sub-Committee}

This sub-committee, a credit to the indefatigability of the nursing profession, covered all areas of psychiatric nursing services, and very quickly established:-

(i) the existing nursing resources for community psychiatry in all three tiers of government. The case loads, for example Addington Hospital, have accounted for 6 new cases daily, with as many as 800 visits per month by the District Nursing Services to Whites and 450 to Coloureds - Staff available: 6 White and 1 Coloured nurse for this purpose;

(ii) the need for a standardised communications and referral system with the final aim of a common record system. Specimen psychiatric referral forms; specimen feedback following psychiatric referral; specimen psychiatric feedback forms were designed, together with guidelines for their usage.

They are in the hands of the State Health Department awaiting approval. Their total acceptance has been by the entire Co-ordinating Committee, so has the acceptance of a variety of disciplines and organisations;

(iii) lines of communication have been clearly demarcated;

(iv) a complete syllabus for a two-week in-service training for community health nurses has been drawn up and this covers every conceivable practical aspect from patient-counselling by nurses, psychologists and social workers through group therapy sessions to psychiatric first aid to progress assessment;

(v) the involvement of industrial nurses and school medical services was not ignored.

At the risk of pressing the point too hard let me say that: the Clinical Sub-Committee has drawn up a blueprint for a comprehensive metropolitan psychiatric service based on population and estimated psychiatric morbidity and this blueprint ranged from inpatient services, adolescent units, detoxification centres to halfway houses.

Urgent needs were established, one such example being a community in Durban of 250000 cared for by only 8 psychiatric sessions per month with 4 Medical Officer sessions, giving a case load of 2600 or 50 patients per hour. This problem was largely met by providing facilities in two other municipal clinics and a reallocation and distribution of professional staff (State Health).

The Child Psychiatric Services Sub-Committee headed by the Professor of Education at the University of Durban-Westville and embracing 17 other persons ranging from clinical psychologists to a paediatrician, have clearly identified their roles and limits and are now setting about co-ordination, exploring possible training facilities with minimal manpower and demonstrating 
the deficiencies in these services.

Well, each sub-committee has covered enormous ground and to take each in turn would indeed take far longer than time permits. Suffice it to say, and this in itself is no mean achievement: each sub-committee has worked singularly hard and so often, in seeking their first, second or third priorities, and have actually solved problems of long standing without ever coming to the main co-ordinating committee at all. What is more, the working together and the informal discussions by the sub-committee chairmen have led to a smooth, integrated, multidisciplinary team working for the community.

This co-ordinating committee can be chaired by any member but the role of the local authority on the subcommittees must indeed be clear.

\section{Community Involvement}

Here indeed the Local Authority Health Department is clearly at its strongest. In Durban, over the last nine months some 14 Neighbourhood Groups have been formed by the health visitors, from all areas of the City and made up of mothers, the wives of men of every occupation. On 15 and 16 th of this month a symposium and panel were arranged by these very groups. Wives brought their husbands to the last day's session. A panel made up to answer questions commonly posed by these very mothers and in fact drawn up by them, were put to the panel of experts - the composition of this panel, which sat to an audience of 300 for over $2 \frac{1}{2}$ hours will illustrate the public interest and demand for mental wellbeing:-

a nursery school teacher;

a clinical psychologist;

an educational psychologist;

a headmaster;

a public health medical specialist.

The role of the local authority in regard to health legislation then, perhaps we will all agree, is indeed vast and ever expanding. 